\title{
Dwarf Mistletoe-Host Interactions in Mixed-Conifer Forests in the Sierra Nevada
}

\author{
Patricia E. Maloney and David M. Rizzo
}

Department of Plant Pathology, University of California, Davis 95616.

Accepted for publication 30 January 2002.

\begin{abstract}
Maloney, P. E., and Rizzo, D. M. 2002. Dwarf mistletoe-host interactions in mixed-conifer forests in the Sierra Nevada. Phytopathology 92: 597-602.

We determined the spatial pattern of dwarf mistletoe (Arceuthobium spp.) associated with two different conifer hosts, white fir (Abies concolor) and Jeffrey pine (Pinus jeffreyi), in forests around the Lake Tahoe Basin and at the Teakettle Experimental Forest, both located in the Sierra Nevada. We also examined a number of host variables and bark beetle incidence to determine how these factors might be involved in the Arceuthobium-conifer interaction. There was no significant relationship between dwarf mistletoe-infected trees and associated bark beetles. We

lated to density but the dwarf mistletoe rating (DMR) was positively correlated to host size. At the Teakettle Forest, dwarf mistletoe incidence on white fir was not correlated with host density but the DMR was correlated with host size. Dwarf mistletoe incidence and DMR on Jeffrey pine were correlated with host density. Individuals, of both conifer species, in all diameter size classes were susceptible to dwarf mistletoe, with the lowest infection rate in the seedling-10-cm-diameter class. Arceuthobium on white fir in Lake Tahoe showed spatial dependence to a range of $20 \mathrm{~m}$. However, Arceuthobium on Jeffrey pine in Lake Tahoe and on white fir at Teakettle showed no clear pattern of spatial structuring. The degree of infection and stand history appear to be important in the spatial dynamics of Arceuthobium spp.
\end{abstract} found the highest incidence of dwarf mistletoe on Jeffrey pine in Lake Tahoe $(87 \%)$, followed by dwarf mistletoe on white fir in Lake Tahoe (30\%), with the lowest incidence on white fir at Teakettle (27\%). Dwarf mistletoe incidence on white fir in our Lake Tahoe grid was not corre-
Additional keywords: disease dynamics, host-pathogen interactions, spatial distribution.
The dwarf mistletoes (Arceuthobium spp.) are considered to be the single most destructive pathogen of commercially valuable conifers in several regions of the western United States and Mexico (8,9). Dwarf mistletoes can retard growth of infected trees and cause extensive losses through direct and indirect mortality (9). However, Arceuthobium spp. also produce large brooms that provide valuable habitat and food resources for wildlife (i.e., birds, raptors, and small mammals) $(2,9,18,19)$. The need to incorporate natural disturbances, such as pathogens and insect pests, in forest management and restoration is one of the key features in the recent forest management and conservation biology literature (4, $12,26,30)$. The study of forest pests is not only important for forest management, but also to understand their role in forest community dynamics.

Dispersal of dwarf mistletoe is generally very localized around a host plant. The seeds of this parasitic plant are forcibly discharged with maximum dispersal distances of approximately $16 \mathrm{~m}$, with most seeds being intercepted within 2 to $4 \mathrm{~m}$ by host needles (9). These seed interception rates are highly variable and depend on stand structure and composition and position of dwarf mistletoe on the host (9). A number of probability distributions governing spore dispersal predict that plant disease generally expands out from a focus center $(3,11,16)$. If dwarf mistletoe seed dispersal is limited to $16 \mathrm{~m}$, we would expect that an infected tree or cluster of infected trees, in close proximity to one another, would be defined as a focus center and expand out as such. Thus, due to the nature of dwarf mistletoe seed dispersal, disease foci may be distinguishable, if they have not already coalesced. With the many Arceuthobium-conifer interactions in the west and in stands with different

Corresponding author: P. E. Maloney; E-mail address: tbntm@telis.org

Publication no. P-2002-0404-01R

(c) 2002 The American Phytopathological Society management histories, we might expect to see this aggregated spatial pattern across different locations and with different Arceuthobium-conifer associations.

Once centers are established, dwarf mistletoe infections generally intensify on individual hosts. Such heavy dwarf mistletoe infections weaken trees and predispose individuals to a number of pests, including bark beetles $(5,20)$. Bark beetle incidence can be high on white fir (Abies concolor) and Jeffrey pine (Pinus jeffreyi), two important species in Sierra Nevada mixed-conifer forests, which are also hosts to Arceuthobium. Bark beetles on Jeffrey pine and white fir differ in their ability to attack and kill conifer hosts predisposed to pathogens (17). The degree to which beetles promote or mitigate destructive outcomes on hosts infected with Arceuthobium may differ with different host-pathogen associations.

In order to understand Arceuthobium patterns of spread, host effects, and bark beetle interactions in the Sierra Nevada, we chose to study mistletoe in two different areas (with different management histories) and two different Arceuthobium spp. over three study sites. Our objectives were to (i) determine the relationships of dwarf mistletoe with host variables, bark beetles, and mortality, (ii) assess the spatial pattern of Arceuthobium on white fir in two different mixed-conifer locations in the Sierra Nevada, and (iii) determine if different species of Arceuthobium on their respective conifer hosts have similar spatial distributions within a 1-ha area.

\section{MATERIALS AND METHODS}

Study species. The two species of Arceuthobium we studied are Arceuthobium abietinum Engelm. Ex Munz f. sp. concoloris, which infects white fir, and Arceuthobium campylopodum Engelm., which infects Jeffrey pine (9). The two main scolytid bark beetles that attack white fir and Jeffrey pine are Scolytus 
ventralis Leconte (27) and Dendroctonus jeffreyi Hopkins (25), respectively. Both are widely distributed throughout the western United States (6).

Study areas. Our study areas are located in the Sierra Nevada of California. We conducted studies during the growing season of 1998 in mixed-conifer locations in the Lake Tahoe Basin $\left(120^{\circ} \mathrm{W}\right.$, $\left.39^{\circ} \mathrm{N}\right)$ and the Teakettle Experimental Forest $\left(119^{\circ} \mathrm{W}, 36^{\circ} \mathrm{N}\right)$. Mixed-conifer forests dominate much of the Lake Tahoe Basin at elevations between 1,793 m (lake level) and 2,125 m. The Lake Tahoe Basin's mixed-conifer forest is composed of white fir (Abies concolor (Gord. \& Glend.) Lindl.), incense cedar (Calocedrus decurrens (Torr.) Florin), Jeffrey pine (P. jeffreyi Grev. \& Balf.), sugar pine ( $P$. lambertiana Dougl.), and ponderosa pine $(P$. ponderosa Laws.), with lesser numbers of red fir (Abies magnifica A. Murr.) and lodgepole pine (P. contorta Loud.) (15). The climate of the Sierra Nevada is characterized by wet winters and dry summers. In the Lake Tahoe Basin, the mean annual winter temperature and summer temperatures are 6 and $24^{\circ} \mathrm{C}$, respectively. The mean annual precipitation is approximately $80 \mathrm{~cm}$ (range is between 50 to $100 \mathrm{~cm}$, depending on aspect and elevation), and above $1,824 \mathrm{~m}$ snow represents $80 \%$ of the yearly precipitation.

The Teakettle Experimental Forest is a 1,300-ha old-growth forest located $80 \mathrm{~km}$ east of Fresno, CA, in the drainage of the north fork of the Kings River. Elevation ranges from $1,980 \mathrm{~m}$ along the eastern boundary to 2,590 $\mathrm{m}$ at the top of the Patterson Mountain along the western boundary. Annual precipitation averages $110 \mathrm{~cm}$ at 2,100 $\mathrm{m}$ and falls mostly as snow between November and April. The Teakettle forest grades from mixed-conifer forest (white fir, sugar pine, incense cedar, Jeffrey pine, and red fir) at the lower elevations to red fir, lodgepole pine, and western white pine at the higher elevations. Soils are generally Xerumbrepts and Xeropsamments, typical of the southwestern slopes of the Sierra Nevada (1).

Field sampling. Three 1-ha grids with $10-\mathrm{m}^{2}$ cells were established in two mixed-conifers stands in the Lake Tahoe Basin and one in the mixed-conifer forest at the Teakettle Forest. In one of the Lake Tahoe grids and the Teakettle grid, we studied the white fir-Arceuthobium abietinum f. sp. concoloris interaction and associated fir engraver beetle, $S$. ventralis, and in the other Lake Tahoe grid we studied the Jeffrey pine-Arceuthobium campylopodum interaction and associated Jeffrey pine beetle, $D$. jeffreyi. Within each $10-\mathrm{m}^{2}$ cell, we recorded diameter at breast height $(\mathrm{dbh})$ for every white fir or Jeffrey pine tree and presence or absence of mistletoe. Diameter at breast height was taken on those trees at least $1.5 \mathrm{~m}$ tall, and trees smaller than $1.5 \mathrm{~m}$ were recorded as seedlings. These numbers were also used to determine density of hosts per cell. Dwarf mistletoe incidence was determined by the presence of cankers, swellings, or brooms, and the presence of the dwarf mistletoe plant on infected branches or stems. If mistletoe was present, the severity of infection was estimated according to the method of Hawksworth (7). This rating

TABLE 1. Grid summaries of mean host, nonhost variables, disease, bark beetles, and mortality from three 1-ha grids with $10010-\mathrm{m}^{2}$ cells in the Lake Tahoe Basin and Teakettle Experimental Forest ${ }^{\mathrm{a}}$

\begin{tabular}{lccc}
\hline Stand and host variables & $\begin{array}{c}\text { Lake Tahoe } \\
\text { Arceuthobium } \\
\text { white fir }\end{array}$ & $\begin{array}{c}\text { Lake Tahoe } \\
\text { Arceuthobium- } \\
\text { Jeffrey pine }\end{array}$ & $\begin{array}{c}\text { Teakettle } \\
\text { Arceuthobium- } \\
\text { white fir }\end{array}$ \\
\hline No. of hosts per cell & $7.4(8.1)$ & $1.6(1.8)$ & $5.1(5.28)$ \\
Density per ha & 743 & 161 & 516 \\
Average host dbh (cm) & $19.01(21.6)$ & $34.80(17.0)$ & $46.52(33.43)$ \\
No. of nonhosts per cell & $3.6(3.6)$ & $4.5(3.5)$ & $3.8(5.01)$ \\
Dwarf mistletoe incidence & $30(37.2)$ & $87(30.6)$ & $27(33.0)$ \\
Dwarf mistletoe rating & $2.0(0.70)$ & $3.5(0.81)$ & $1.5(0.55)$ \\
Trees with bark beetle & $21 \%(26.7)$ & $37 \%(36.1)$ & $10 \%(22.9)$ \\
Mortality & $23 \%(26.6)$ & $44 \%(37.1)$ & $12 \%(23.5)$ \\
\hline
\end{tabular}

a Values in parentheses are standard deviations. $\mathrm{dbh}=$ diameter at breast height. system is based on visual estimation of infection intensity of the crown. The tree crown is divided into thirds (top, middle, and lower) and each third is rated for intensity: $0=$ no infected branches, $1=\leq 50 \%$ of branches are infected, and $2=>50 \%$ of branches are infected. Dwarf mistletoe ratings for each third are added and a tree rating is obtained ranging from 0 (no infection) to 6 (heavy infection), which will be referred to as the DMR or dwarf mistletoe rating. Stems and branches were examined for the presence of bark beetles (i.e., boring dust, pitch tubes, and galleries). Dead trees were examined to determine apparent mortality agents. We also recorded the dbh and species of nonhost trees within each cell to determine local stand density.

Statistical and spatial analyses. Pearson correlation analysis was used to determine relationships between dwarf mistletoe incidence and select biological variables. Data were transformed if parametric assumptions were violated and where transformations did not improve normality, a nonparametric test, Spearman's rank, was used. A Bonferroni correction was applied for correlation analyses of each of the three dwarf mistletoe data sets. The analyses described above used data (averages for all variables per cell except density, which is reported as the total number of trees per cell) from each $10-\mathrm{m}^{2}$ cell within each 1-ha grid, all with an $n=100$. All statistical procedures were performed using SAS (version 6.0, SAS Institute Inc., Cary, NC). Chi-square analysis was used to determine if all size classes were equally likely to be infected with dwarf mistletoe.

To analyze spatial patterns of Arceuthobium, we used variograms (semivariance) $(10,13,24)$. Variograms determine the degree of spatial autocorrelation or spatial dependence. Values that remain constant mean that the variance does not change with distance, indicating that there is some continuity in the variability across space (24). Small variogram values at short lags or distances correspond to data that are more similar or spatially dependent, whereas large variogram values indicate data that are more dissimilar or spatially independent (24). For spatial analyses of Arceuthobium incidence, we used the residuals from the regression of disease incidence on host density. Real and McElhany (21) recommend using the residuals to uncouple the spatial structure of disease from the spatial structure of the host so that one is left with the sole effect of space. Variograms were standardized so that comparisons could be made between the mixed-conifer data sets. A best fit model was calculated for all three analyses using GS+ software (Gamma Design Software, Plainwell, MI). The Tahoe and Teakettle white fir data sets were fit to exponential models, and the Tahoe Jeffrey pine data set was fit to a spherical model. All variograms were run with GS+ software.

\section{RESULTS}

Dwarf mistletoe was present throughout all grids, with the highest incidence of dwarf mistletoe (based on averages from 100 cells per grid) on Jeffrey pine in Lake Tahoe (87\%), followed by

TABLE 2. Correlation (Pearson or Spearman) summaries for dwarf mistletoe (dwm), bark beetles, host density, and mortality for three 1-ha grids with 100 $10-\mathrm{m}^{2}$ cells, $n=100$ for each correlation ${ }^{\mathrm{a}}$

\begin{tabular}{lccc}
\hline Correlation & $\begin{array}{c}\text { Lake Tahoe } \\
\text { Arceuthobium } \\
\text { white fir }\end{array}$ & $\begin{array}{c}\text { Teakettle } \\
\text { Arceuthobium- } \\
\text { white fir }\end{array}$ & $\begin{array}{c}\text { Lake Tahoe } \\
\text { Arceuthobium- } \\
\text { Jeffrey pine }\end{array}$ \\
\hline Density $\times$ dwm & 0.18 & 0.28 & $\underline{0.85}$ \\
$\begin{array}{l}\text { Density } \times \text { mistletoe rating } \\
\text { Mistletoe rating } \times \mathrm{dbh}^{\mathrm{b}}\end{array}$ & 0.11 & 0.21 & $\underline{0.57}$ \\
Bark beetle $\times$ dwm & $\underline{0.37}$ & $\underline{0.23}$ & 0.13 \\
$\begin{array}{l}\text { Density } \times \text { bark beetle } \\
\text { Bark beetle } \times \text { mortality }\end{array}$ & $\underline{0.45}$ & 0.11 & 0.30 \\
\hline
\end{tabular}

${ }^{a}$ Underlined values indicate a significant correlation with the Bonferroni correction $(P \leq 0.008)$.

${ }^{\mathrm{b}} \mathrm{dbh}=$ diameter at breast height in centimeters. 
dwarf mistletoe on white fir in Lake Tahoe (30\%), and the lowest incidence on white fir at the Teakettle Forest (27\%) (Table 1). Patterns of bark beetle incidence were similar to the patterns of dwarf mistletoe abundance. D. jeffreyi on Jeffrey pine had the highest incidence (44\%), followed by S. ventralis on white fir $(23 \%)$ in Lake Tahoe and the Teakettle Forest (12\%). On average, DMR were highest on Jeffrey pine followed by white fir in Lake Tahoe, with white fir at the Teakettle having the lowest DMR (Table 1). We found that dwarf mistletoe incidence on white fir in the Lake Tahoe grid was not correlated to density, but the DMR was significantly and positively correlated to host size (Table 2). At the Teakettle Forest, we found a significant but weak correlation between DMR on white fir and host size (Table 2). However, dwarf mistletoe incidence and severity on Jeffrey pine were significant and positively correlated with host density, but the DMR was not correlated with host size (Table 2).

We found no relationship between white fir and Jeffrey pine trees with dwarf mistletoe and the incidence of $S$. ventralis or $D$. jeffreyi, respectively (Table 2). In Lake Tahoe, bark beetles, both $S$. ventralis and $D$. jeffreyi, were significant and positively correlated with host density (Table 2). There was no relationship between white fir density and $S$. ventralis incidence at the Teakettle Forest (Table 2). However, at all three locations, bark beetle incidence was significant and positively correlated with host mortality (Table 2).

Individuals of both white fir and Jeffrey pine in all diameter size classes were susceptible to dwarf mistletoe (Fig. 1). The greatest number of white fir trees at Lake Tahoe infected with dwarf mistletoe were those individuals less than 30-cm dbh (Fig. 1A). Dwarf mistletoe infection on white fir at the Teakettle Forest was evenly distributed across most diameter size classes (Fig. 1C). The greatest number of Jeffrey pine trees infected with dwarf mistletoe in Lake Tahoe were between $20-$ to $50-\mathrm{cm}$ dbh (Fig. 1B). Dwarf mistletoe was found on all sizes of hosts; however, chi-square analysis revealed that dwarf mistletoe was significantly less common and much lower than expected on small individuals in the seedling-10-cm diameter size class for Lake Tahoe white fir $\left(\chi^{2}=120.51, P \leq 0.01\right.$, df $\left.=6\right)$, Lake Tahoe Jeffrey pine $\left(\chi^{2}=\right.$ 234.24, $P \leq 0.01, \mathrm{df}=6)$, and Teakettle white fir $\left(\chi^{2}=153.31, P \leq\right.$ 0.01 , df =6) (Fig. 1).

Hosts were widely distributed throughout the three survey grids. In the white fir, Lake Tahoe grid, fir trees were present in $92 \%$ of the cells and at the Teakettle forest, fir trees were present in $88 \%$ of the cells. Jeffrey pine trees in Lake Tahoe were present in $84 \%$ of the cells.

The fir engraver beetle, $S$. ventralis, was widespread in our Lake Tahoe grid (Fig. 2D) and more patchy on white fir at the Teakettle Experimental Forest (Fig. 2E). D. jeffreyi appeared widely distributed throughout the Lake Tahoe grid and its distribution was very similar to the distribution of dwarf mistletoe (Fig. 2F and $\mathrm{C}$ ).

Dwarf mistletoe incidence on white fir in Lake Tahoe showed a degree of spatial structure, with $89 \%$ of model sample variance spatially dependent to a range of $20 \mathrm{~m}$ (Fig. 3A). Dwarf mistletoe infection was heavy on Jeffrey pine in our Lake Tahoe grid and appears to be widely distributed throughout the grid (Fig. 3B). The variogram of dwarf mistletoe incidence on Jeffrey pine showed no spatial dependence (Fig. 3B). However, there is a dip in the variogram at $35 \mathrm{~m}$ where the sample variance is low. This sudden decrease in the variogram is often referred to as a "hole effect." Hole effects can be something that occurs in data sets in which there is a natural repetition, such as the repetition of disease focus centers, or they can be viewed as undesirable noise in a data set (10). More information would be needed to discern whether this is noise or some biological pattern. The variogram for dwarf mistletoe on white fir at the Teakettle Experimental Forest also showed no spatial dependence (Fig. 3C). However, the variogram values remain somewhat constant, ranging between 0.825 to 1.15 , poten- tially indicating that there is some continuity in the variability of dwarf mistletoe across this space, even though there is no spatial structuring.

\section{DISCUSSION}

Host density had little or no effect on the white fir-Arceuthobium interaction in Lake Tahoe and at Teakettle. However, incidence and severity in the Jeffrey pine-Arceuthobium interaction was strongly correlated to host density. One possible explanation for this could be the differences in canopy architecture between fir and pine. Fir trees have a denser canopy so that dispersing seeds of mistletoe might be more likely to be intercepted within the

\section{$\mathbf{A}$}

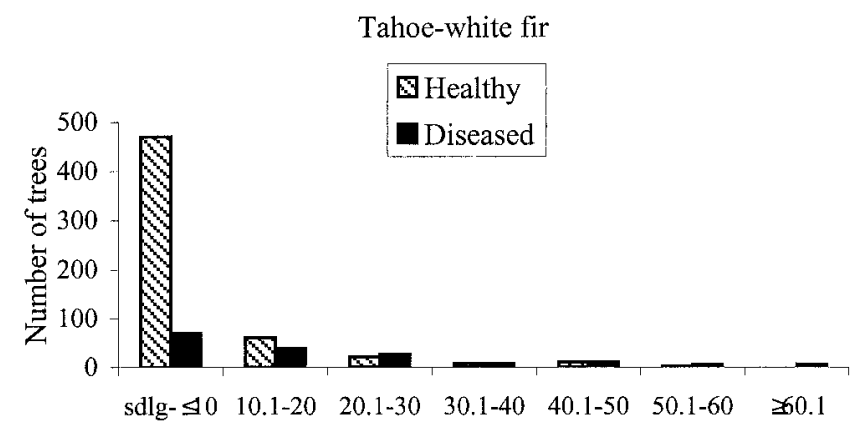

Diameter size class $(\mathrm{cm})$

B



C



Diameter size class $(\mathrm{cm})$

Fig. 1. Number of healthy and diseased trees with dwarf mistletoe for all mistletoe-host interactions from $\mathbf{A}$ and $\mathbf{B}$, Lake Tahoe and $\mathbf{C}$, Teakettle. 
same white fir individual. Pine, on the other hand, has a more open canopy, thus dispersing mistletoe seeds are more likely to land on a nearby individual. We also found in the white firArceuthobium interaction that the larger the tree, generally the more intense the infections. Other studies in southeast Alaska and the southwestern United States have shown this positive relationship with dwarf mistletoe severity and host size $(22,29)$. The more closed canopy architecture of white fir trees may lead to more within-tree interception of dispersing dwarf mistletoe seeds over time. However, this size relationship was not found for the Jeffrey pine-Arceuthobium interaction.

Because infected areas become nutrient sinks at the expense of healthy crown areas, disease can reduce overall tree vigor (9) and often predispose trees to bark beetles. However, the strength of this interaction can vary with different dwarf mistletoe-conifer associations (9). Our study found no strong positive relationship between dwarf mistletoe-infected hosts and bark beetle incidence. $S$. ventralis and $D$. jeffreyi were somewhat widespread in the Lake
Tahoe grids, while $S$. ventralis appeared patchy in the Teakettle grid, but in all cases, incidence of bark beetles did not appear to track mistletoe-infected hosts. Infection levels may be low enough that some trees are still relatively healthy, so predisposition to bark beetles may not be occurring.

Generally all size classes were susceptible to dwarf mistletoe but small individuals, $<10$-cm-dbh, were less likely to become infected than larger individuals for both white fir and Jeffrey pine at all locations. This is not to say that small individuals are more resistant, but due to their position in the canopy, small individuals are distant from the crowns of infected dominant trees and may be less likely to become infected because of within-tree interception. However, as the individual trees $(<10-\mathrm{cm}-\mathrm{dbh})$ become larger, they may present a bigger "target" for dispersing dwarf mistletoe seeds. This phenomena has been observed with white pine blister rust on whitebark pine and western white pine hosts $(14,28)$.

It has been shown that approximately $40 \%$ of all dispersed mistletoe seeds can be intercepted by trees within $16 \mathrm{~m} \mathrm{(9),} \mathrm{in}$
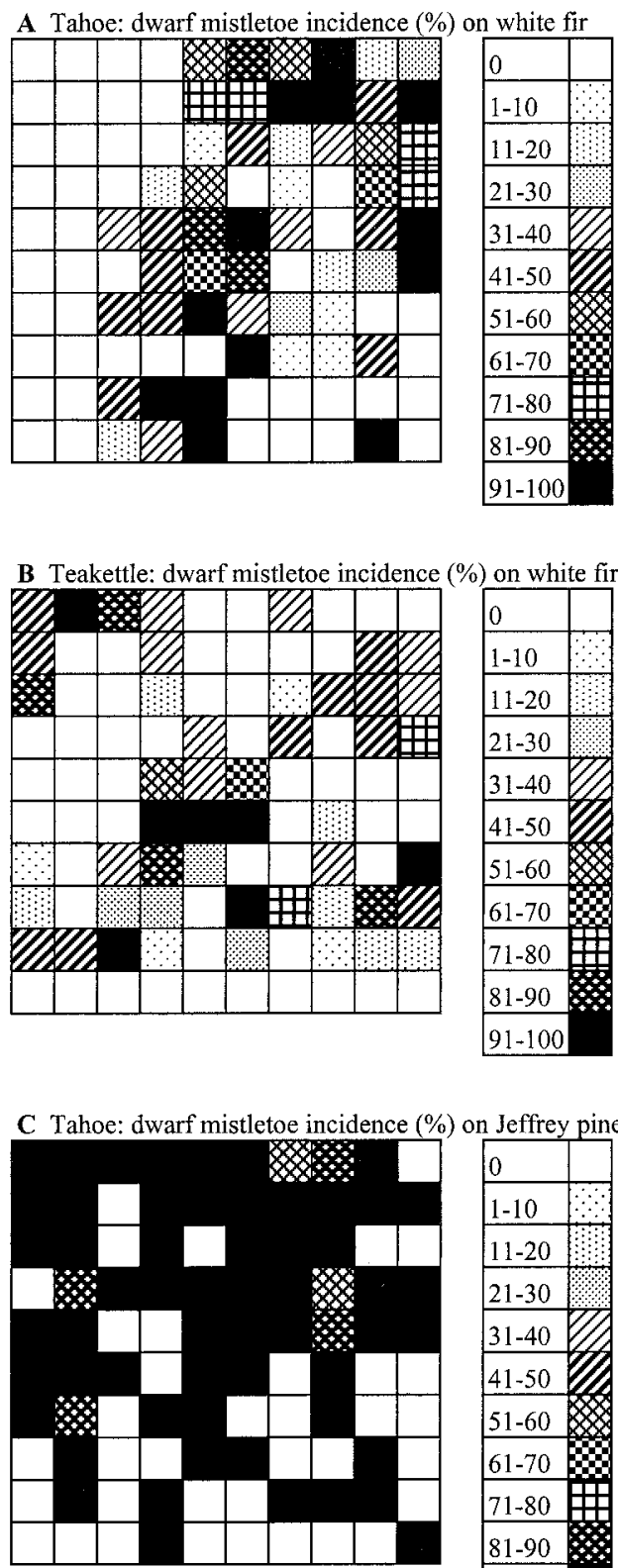

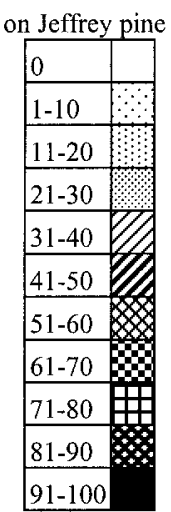


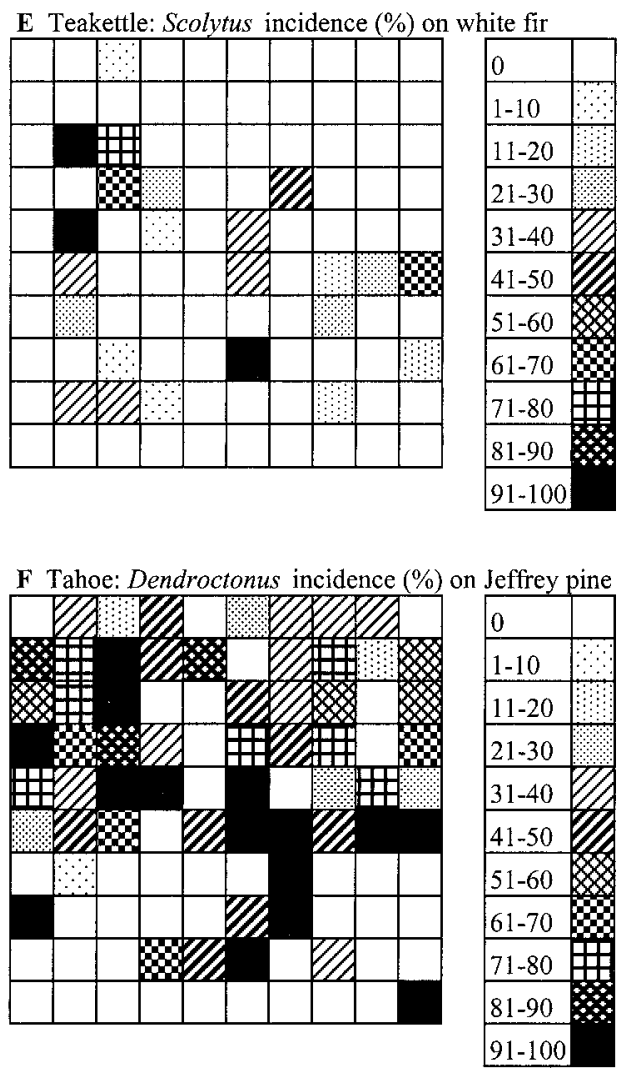

Fig. 2. A 1-ha grid map of dwarf mistletoe incidence in each 10- $\mathrm{m}^{2}$ cell for A, Tahoe-white fir, B, Teakettle-white fir, and $\mathbf{C}$, Tahoe-Jeffrey pine. One-hectare grid map of Scolytus and Dendroctonus spp. incidence in each $10-\mathrm{m}^{2}$ cell for $\mathbf{D}$, Tahoe-white fir, E, Teakettle-white fir, and $\mathbf{F}$, Tahoe-Jeffrey pine. Gray color scale indicates the percent (for dwarf mistletoe and bark beetle incidence) in a given $10-\mathrm{m}^{2}$ cell. 
A

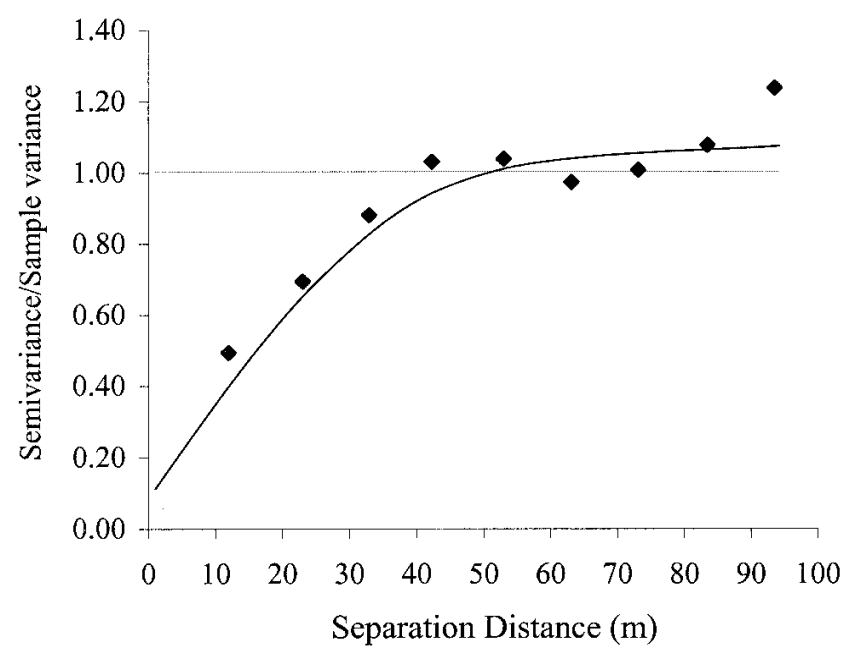

$\mathbf{B}$

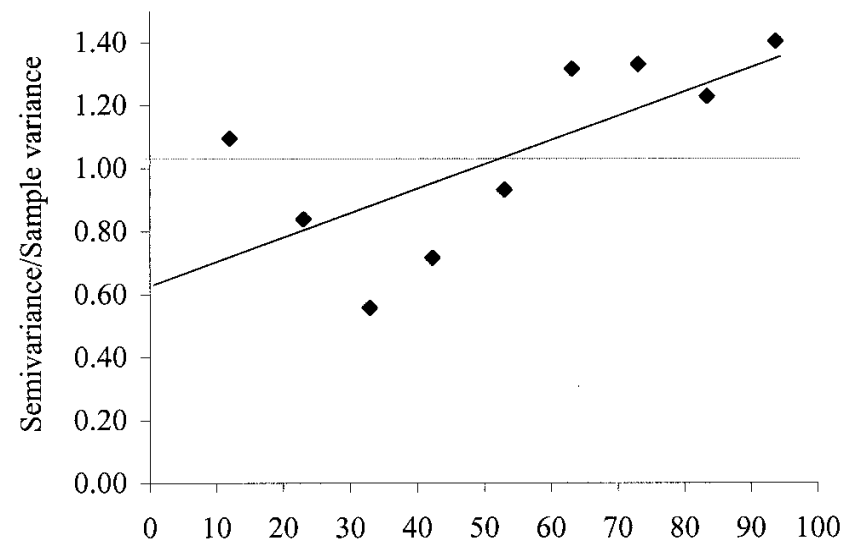

Separation Distance (m)

C



Fig. 3. Isotropic variograms for dwarf mistletoe incidence on white fir at $\mathbf{A}$, Lake Tahoe and $\mathbf{C}$, Teakettle Experimental Forest and B, dwarf mistletoe incidence on Jeffrey pine at Lake Tahoe. which case focus centers should be distinguishable. Other distinguishable foci such as root disease centers expand and even contract over time with growth, dispersal, mortality, and management (23). However, some disease foci may not always be evident due to a number of stand characteristics (history, structure, composition, and condition) and time since infection. We did find a degree of spatial structuring for the white fir-Arceuthobium interaction in Lake Tahoe, in which these focus centers are spatially structured up to $20 \mathrm{~m}$. This area has been logged and the few large residual trees with mistletoe had low to moderate severity ratings. The largest tree in the grid was 190-cm-dbh with a mistletoe severity rating of 3 (moderate infection). White fir is the dominant species in this stand (Table 1) and this coupled with low to moderate DMR appears to have maintained these dwarf mistletoe focus centers.

Arceuthobium spp. on Jeffrey pine in Lake Tahoe and on white fir at the Teakettle showed no clear pattern of spatial structuring. Stand history and composition might be responsible for the lack of maintenance of disease foci. In the Teakettle Forest, which has not been logged, Arceuthobium infection on white fir was relatively low throughout the sampled stand, even though white fir is one of the dominant species in this stand. Given enough time, individual infection centers may have coalesced, showing no signs of spatial structuring. The Lake Tahoe location with Jeffrey pine has also experienced logging, and dwarf mistletoe on Jeffrey pine was significantly different and higher in logged stands compared with unlogged stands (14). Arceuthobium campylopodum infection and severity on Jeffrey pine was relatively high, and it appears that these centers have also coalesced. At the Teakettle location, these centers have probably taken a fair amount of time to coalesce, whereas in the Tahoe location, the spread of dwarf mistletoe and subsequent coalescing of centers most likely occurred over a much shorter time, given the high levels of infection.

We have shown that Arceuthobium-conifer interactions and spread can vary depending on stand history/conditions and host species. Stands in late-seral or old-growth conditions may have low to moderate levels of dwarf mistletoe infection. In the case of white fir trees infected with Arceuthobium abietinum f. sp. concoloris, spread may be slow over time. Even when stands have been logged, focus centers of Arceuthobium on white fir are still distinguishable. However, in the case of Arceuthobium campylopodum infection on Jeffrey pine, logging appears to play a role in increased infection and intensity. Thus, a number of factors, both cultural and biological, should be considered in forest management and restoration objectives in mixed-conifer forests in the western United States, which are host to a number of dwarf mistletoe species.

\section{ACKNOWLEDGMENTS}

This work was supported by the U.S. EPA (R82543) Center for Ecological Health Research at UC Davis. Although the information in this document has been funded in part by the U.S. EPA, it may not necessarily reflect the views of the Agency and no official endorsement should be inferred. We thank M. Barbour, M. North, and two anonymous reviewers for helpful comments and criticisms of an earlier draft and T. Burt, G. Slaughter, and M. Smith for field assistance.

\section{LITERATURE CITED}

1. Anonymous. 1993. Soil survey of Sierra National Forest Area, CA. U.S. Dep. Agric. For. Serv. Publ.

2. Bennetts, R. E., White, G. C., Hawksworth, F. G., and Severs, S. E. 1996. The influence of dwarf mistletoe on bird communities in Colorado ponderosa pine forests. Ecol. Appl. 6:899-909.

3. Burdon, J. J. 1987. Diseases and Plant Population Biology. Cambridge University Press, Cambridge.

4. Christensen, N. L. 1997. Managing for heterogeneity and complexity on dynamic landscapes. Pages 167-186 in: The Ecological Basis of Conservation: Heterogeneity, Ecosystems, and Biodiversity. S. T. A. Pickett, R. 
S. Ostfeld, M. Shachak, and G. E. Likens, eds. Chapman and Hall, New York.

5. Ferrell, G. T. 1996. The influence of insect pests and pathogens in the Sierra forests. Pages 1172-1192 in: Sierra Nevada Ecosystem Project Report to Congress. Vol. II, Assessments and Scientific Basis for Management Options. Univ. Calif., Cent. Water Wildl. Resour., Davis.

6. Furniss, R. L., and Carolin, V. M. 1977. Western forest insects. U.S. Dep. Agric. For. Serv. Misc. Publ. 1339.

7. Hawksworth, F. G. 1977. The 6-class dwarf mistletoe rating system. U.S. For. Serv. Rocky Mt. For. Range Exp. Stn. Gen. Tech. Rep. RM-48.

8. Hawksworth, F. G., and Shaw, C. C. 1984. Damage and loss caused by dwarf mistletoe in coniferous forests of western North America. Pages 285-297 in: Plant Disease: Infection, Damage, and Loss. R. K. S. Wood and G. J. Jellis, eds. Blackwell Scientific Publications, Oxford.

9. Hawksworth, F. G., and Wiens, D. 1996. Dwarf mistletoes: Biology, pathology, and systematics. U.S. Dep. Agric. For. Serv. Agric. Handb. 709.

10. Isaaks, E. H., and Srivastava, R. M. 1989. An Introduction to Applied Geostatistics. Oxford University Press, New York.

11. Jeger, M. J. 1987. The potential of analytic compared with simulation approaches to modeling in plant disease epidemiology. Pages 255-281 in: Plant Disease Epidemiology: Population Dynamics and Management. Vol. I. K. J. Leonard and W. E. Fry, eds. Macmillan Publishers, New York.

12. Landres, P. B., Morgan, P., and Swanson, F. J. 1999. Overview of the use of natural variability concepts in managing ecological systems. Ecol. Appl. 9:1179-1188.

13. Legendre, P., and Fortin, M. J. 1989. Spatial pattern and ecological analysis. Vegetatio 80:107-138.

14. Maloney, P. E. 2000. Topics in forest pathology and ecology in the Sierra Nevada and the Sierra San Pedro Martir, Baja. Ph.D. diss. University of California, Davis.

15. Manley, P. N., Fites-Kaufman, J. A., Barbour, M. G., Rizzo, D. M., and Schlesinger, M. D. 2000. Biological integrity. Pages 403-598 in: The Lake Tahoe Watershed Assessment. D. D. Murphy and C. M. Knopp, eds. Lake Tahoe Basin Management Unit, South Shore, CA. U.S. Dep. Agric. For. Serv. Gen. Tech. Rep. 175.

16. Minogue, K. P. 1989. Diffusion and spatial probability models for disease spread. Pages 127-143 in: Spatial Components of Plant Disease Epidemics. M. J. Jeger, ed. Prentice Hall, Englewood Cliffs, NJ.

17. Paine, T. D., Raffa, K. F., and Harrington, T. C. 1997. Interactions among scolytid bark beetles, their associated fungi, and live host conifers. Annu.
Rev. Entomol. 42:179-206.

18. Parks, C. G., and Bull. E. L. 1997. American marten use of rust and dwarf mistletoe brooms in northeastern Oregon. West. J. Appl. For. 12:131-133.

19. Parks, C. G., Bull, E. L., Tinnin, R. O., Shepherd, J. F., and Blumton, A. K. 1998. Wildlife use of dwarf mistletoe broom. Pages 26-27 in: Proc. West. Int. For. Dis. Work Conf., 46th. L. Trummer, ed. U.S. For. Serv., Anchorage, AK.

20. Raffa, K. F., and Berryman, A. A. 1982. Accumulation of monoterpenes and associated volatiles following fungal inoculation of grand fir with a fungus vectored by the fir engraver Scolytus ventralis (Coleoptera: Scolytidae). Can. Entomol. 114:797-810.

21. Real, L. A., and McElhany, P. 1996. Spatial pattern and process in plantpathogen interactions. Ecology 77:1011-1025.

22. Reich, R. M., Mielke, P. W., Jr., and Hawksworth, F. G. 1991. Spatial analysis of ponderosa pine with dwarf mistletoe. Can. J. For. Res. 21:1808-1815.

23. Rizzo, D. M., Slaughter, G. W., and Parmeter, J. R., Jr. 2000. Enlargement of canopy gaps associated with a fungal pathogen in Yosemite Valley, California. Can. J. For. Res. 30:1501-1510.

24. Rossi, R. E., Mulla, D. J., Journel, A. G., and Franz, E. H. 1992. Geostatistical tools for modeling and interpreting ecological spatial dependence. Ecol. Monogr. 62:277-314.

25. Smith, R. H. 1971. Jeffrey pine beetle. U.S. Dep. Agric. For. Pest Leafl. 11.

26. Spies, T. A., and Turner, M. G. 1999. Dynamic forest mosaics. Pages 95160 in: Maintaining Biodiversity in Forest Ecosystems. M. L. Hunter, ed. Cambridge University Press, Cambridge, UK.

27. Stevens, R. E. 1956. Fir engraver beetle. U.S. Dep. Agric. For. Pest Leafl. 13.

28. Tomback, D. T., Clary, J. K., Koehler, J., Hoff, R. J., and Arno, S. F. 1995. The effects of blister rust on post-fire regeneration of whitebark pine: The Sundance burn of northern Idaho (U.S.A.). Conserv. Biol. 9:654-664

29. Trummer, L. M., Hennon, P. E., Hansen, E. M., and Muir, P. S. 1998. Modeling the incidence and severity of hemlock dwarf mistletoe in 110year-old wind-disturbed forests on Southeast Alaska. Can. J. For. Res. 28:1501-1508

30. Weins, J. A. 1997. The emerging role of patches in conservation biology. Pages 93-107 in: The Ecological Basis of Conservation: Heterogeneity, Ecosystems, and Biodiversity. S. T. A. Pickett, R. S. Ostfeld, M. Shachak, and G. E. Likens, eds. Chapman and Hall, New York. 